\title{
Performance and Real-time Control of a Novel SBR Based on Simulating Photovoltaic Aeration for Organics Removal
}

\author{
Fangshu Ma and Beihai Zhou* \\ Department of Environmental Engineering, School of Civil and Environmental Engineering, University of Science and Technology \\ Beijing, Beijing 100083, China \\ *Corresponding author
}

\begin{abstract}
A novel SBR based on simulating photovoltaic aeration for organics removal was established for rural sewage treatment. Short-term effects of aeration rate and temperature on soluble chemical oxygen demand (SCOD), ammonium $\left(\mathrm{NH}_{4}{ }^{+}-\mathrm{N}\right)$ and dissolved total phosphorous (DTP) removal processes were investigated, and suitable real-time control parameters for organics removal process were selected. The results showed that organic removal process can be divided into the rapid degradation stage and the recalcitrant degradation stage. In the organic matter rapid degradation stage, when temperature was constant $\left(25^{\circ} \mathrm{C}\right)$, the increase in aeration rate resulted in a positive impact upon the SCOD decrease rate and the amount of $\mathrm{NH}_{4}{ }^{+}-\mathrm{N}$ assimilated by heterotrophic bacteria. The slope changes in $\mathrm{DO}$ profiles $(\mathrm{d} D O / \mathrm{d} t)$ were found to better represent the organic degradation process, which could be used for real-time control of the organics removal process after smoothing.
\end{abstract}

Keywords-PV aeration; SBR; organic removal process; real-time control; rural sewage

\section{INTRODUCTION}

The proportions of domestic sewage treated are as low as $18.1 \%$ for county towns and $4.9 \%$ for rural villages by 2009 , in China ${ }^{[1]}$. The direct discharge of those poorly treated or untreated sewage containing large amount of nitrogen, phosphorus and organic matter is responsible for many water bodies pollution ${ }^{[2,3]}$ and is a potential threat to public health ${ }^{[4,5]}$.

Biological wastewater treatment technologies have been successfully used for rural sewage treatment, and are able to remove COD, nitrogen and phosphorus effectively. However the high energy consumption of these technologies is often cited as the main barrier to their wide application in rural areas ${ }^{[6]}$. In order to overcome this limitation, some researchers proposed to use the hybrid energy system combining conventional and the renewable energy resources to meet the energy requirement of the rural sector wastewater treatment plants [7], and others attempted to solely use the novel photovoltaic technology without batteries for rural sewage treatment, further reducing the dependence of sewage treatment facilities on grid system and the construction costs.

Han et al. [6] reported an innovative integrated system utilizing solar energy as power for decentralized wastewater treatment in Beijing, China. Additionally, our previous study using a pilot-scale photovoltaic intermittent aeration $\mathrm{A} / \mathrm{O}$ reactor for rural domestic wastewater treatment in Dali, Yunnan province, China. Compared to the anaerobic reactor, the photovoltaic intermittent aeration $\mathrm{A} / \mathrm{O}$ reactor could significantly improve the $\mathrm{COD}, \mathrm{NH}_{4}{ }^{+}-\mathrm{N}, \mathrm{TN}$ and TP removal efficiency, and it was successfully applied to engineering practice ${ }^{[8]}$.

The ORP and DO levels can successfully indicate the oxidative and biological state of the wastewater, and $\mathrm{pH}$ is a good indicator of ongoing biological reactions ${ }^{[9,10]}$. However, the usefulness of the information provided by those bending points is site-dependent ${ }^{[11]}$. For different COD/TKN ratios of raw wastewater, the time points when the bending points in ORP and DO profiles appear vary largely, and there is no clear bending points in some conditions ${ }^{[12-14]}$

The objective of this work is to removal organic matter in rural domestic wastewater treatment by a novel SBR based on simulating photovoltaic intermittent aeration to reduce operational cost and avoid inhibition on subsequent nitrification, and investigate the effects of temperature and aeration rate on organic matter and nutrients removal processes. In addition, the correlation between the COD removal process and the ORP, DO and $\mathrm{pH}$ profiles was identified for potential reel-time on-line application.

\section{MATERIALS AND METHODS}

\section{A. Experimental Set-up}

The SBR reactor used in this study was a $28.3 \mathrm{~L}$ plexiglass vessel with the working volume of $25 \mathrm{~L}$ and $190 \mathrm{~mm}$ in diameter and $1000 \mathrm{~mm}$ in height.

Since the solar energy is abundant in the southwest of China [15], offering significant opportunity for the application of photovoltaic aeration for wastewater treatment, the operation mode of the reactor is designed according to the solar resource of these areas. The SBR was working in daytime (8:15-17:25) and idling at night (17:25- next day 8:15). During the first $5 \mathrm{~min}$ of the cycle, $12.5 \mathrm{~L}$ wastewater was delivered into the reactor and the same amount of liquid was discharged at the end of the cycle, giving a volumetric replacement ratio of $50 \%$. 


\section{B. Seed Sludge and Wastewater Composition}

The reactor was seeded with the return sludge of a local municipal wastewater treatment plant in Beijing, China. The mixed liquor suspended solids (MLSS) concentration is about $1000 \mathrm{mg} / \mathrm{L}$.

The influent characteristics were as follows: COD of $269.4 \pm 56.5 \mathrm{mg} / \mathrm{L}, \mathrm{TN}$ of $47.8 \pm 10.2 \mathrm{mg} / \mathrm{L}$, TP of $5.5 \pm 0.8 \mathrm{mg} / \mathrm{L}$, $\mathrm{NH}_{4}{ }^{+}-\mathrm{N}$ of $36.2 \pm 7.1 \mathrm{mg} / \mathrm{L}, \mathrm{NO}_{3}{ }^{-}-\mathrm{N}$ of $0.4 \pm 0.2 \mathrm{mg} / \mathrm{L}$.

\section{Analytical Methods}

The $\mathrm{pH}$ was detected on line using Hach HQ30d meter. ORP and DO were monitored by Hach HQ40d meter. The SBR system performance was monitored by a variety of parameters including SCOD, $\mathrm{NH}_{4}{ }^{+}-\mathrm{N}, \mathrm{NO}_{3}{ }^{-}-\mathrm{N}, \mathrm{NO}_{2}{ }^{-}-\mathrm{N}$ and DTP. All chemical analyses were performed in accordance with standard methods given in APHA ${ }^{[16]}$. Samples were collected at 10-30min intervals. All samples were analyzed after filtration through $0.45 \mu \mathrm{m}$ filter paper.

\section{RESULTS AND DISCUSSION}

\section{A. The Effect of Aeration Intensity on Pollutants Removal Processes}

Figure 1 shows the variations of $\mathrm{SCOD}, \mathrm{NH}_{4}{ }^{+}-\mathrm{N}, \mathrm{NO}_{3}^{-}-\mathrm{N}$, $\mathrm{NO}_{2}{ }^{-}-\mathrm{N}$ and DTP during the reaction stage of the first cycle under the aeration rate of $1.0 \mathrm{~L} / \mathrm{min}, 0.5 \mathrm{~L} / \mathrm{min}$, respectively, while the water temperature was maintained at $25^{\circ} \mathrm{C}$. The organic removal process in all conditions can be divided into the rapid degradation stage and the recalcitrant degradation stage. In the rapid degradation stage, the higher the aeration rate, the faster SCOD decrease and the greater amount of $\mathrm{NH}_{4}{ }^{+}-\mathrm{N}$ was assimilated by heterotrophic bacteria. This result is in agreement with the observation of Tang et al. ${ }^{[17]}$.

Nitrate and nitrite were less than $0.5 \mathrm{mg} / \mathrm{L}$ during the organic matter rapid degradation stage under the aeration rate of $1.0 \mathrm{~L} / \mathrm{min}$ and $0.5 \mathrm{~L} / \mathrm{min}$. Both nitrate and nitrite increased due to nitrification during the organic matter recalcitrant degradation stage, however, the nitrification rate was much lower than reported conventional SBR used for organic matter removal ${ }^{[17,18]}$, while the influent COD was lower than the inhibition level ${ }^{[18]}$. The main reason for the low nitrification rate in this study could be that nitrification was hampered by long-term anoxic or anaerobic condition. Hu et al. ${ }^{[19]}$ showed that the average specific ammonia oxidation rate and average specific nitrite oxidation rate exhibited an decrease of $46.8 \%$ and $36.3 \%$, respectively, after $12 \mathrm{~h}$ anoxic treatment.

Biological phosphorus removal process is regulated by multiple operational factors, while it is indeed capable of efficient phosphorus removal performance, the stability and reliability can be a problem $[20,21]$. In this study, the DTP increased during the earlier stage of reaction due to phosphorus release. Subsequently, a continuous decrease was found..

Under the aeration of $0.5 \mathrm{~L} / \mathrm{min}$, phosphorus removal was not obvious, since the insufficient SCOD resulted in inadequate phosphorus release (Figure 1b).
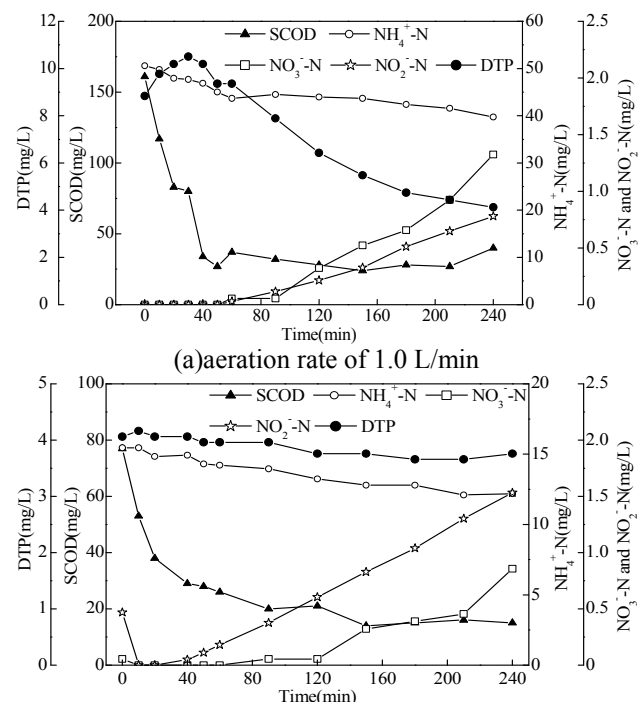

(b)aeration rate of $0.5 \mathrm{~L} / \mathrm{min}$

FIGURE I. EFFECTS OF AERATION RATE ON POLLUTANTS REMOVAL PROCESSES

\section{B. Implication of DO Profiles}

There were obvious breaking points in SCOD profiles. In practice, if the important points are accurately captured and cut-off the aeration immediately can not only ensure the treatment efficiency, but also avoid excessive aeration, reduce energy consumption and increase facility treating capacity.

Offline measurement of COD is often time consuming and costly, and because of time lapse may decrease the control accuracy of the system ${ }^{[27]}$. Real-time control of SBR is a widely accepted and growing practice for these simple sensors offer an attractive alternative to offline measurement because they are characterized by low investment and maintenance costs, and a straightforward operation.

Figure 2 shows the changes of SCOD with the ORP, $\mathrm{pH}$ and DO profiles in the first cycle of the SBR under different operation conditions. Some researchers reported that ORP is a robust indirect real-time control parameter for nutrients removal in SBRs ${ }^{[10-14]}$. However, in this study, the ORP profiles show poor repeatability and weak correspondence with COD degradation process (Figure 2), the undesirable results may be caused by the probe fouling after immersed in wastewater for certain period ${ }^{[28]}$.

With respect to the $\mathrm{pH}$ profile pattern, a decrease was observed in the beginning of the REACTION stage. Since aeration was initiated in this stage, the resuspension of the settled activated sludge resulted in the $\mathrm{pH}$ reduction, probably due to fermentation byproducts ${ }^{[29]}$. The $\mathrm{pH}$ kept decreasing until an turning point appeared indicating the fermentation byproducts were gradually consumed and $\mathrm{CO}_{2}$ expelled from the solution by air-stripping raised $\mathrm{pH}$. The differences in $\mathrm{pH}$ profiles may be caused by the variation in the loading rate due to the influent strength fluctuation and the extend of biological reactions, e.g. ammonification, nitrification/denitrification and phosphorus release/uptake under different operation conditions. Therefore, if the $\mathrm{pH}$ profile was used for real-time control of the 
reaction stage, failure of the organics removal process control would have resulted during the operation.

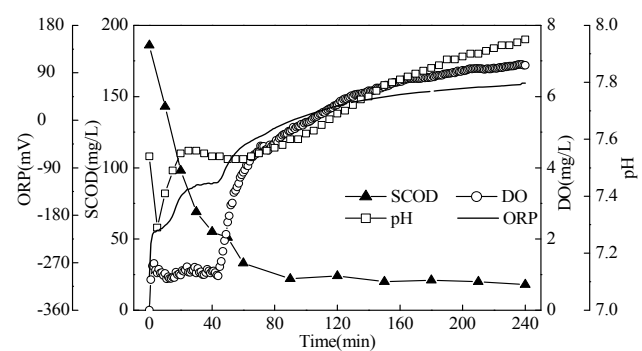

(a)aeration rate $=1 \mathrm{~L} / \mathrm{min}, \mathrm{T}=25^{\circ} \mathrm{C}$

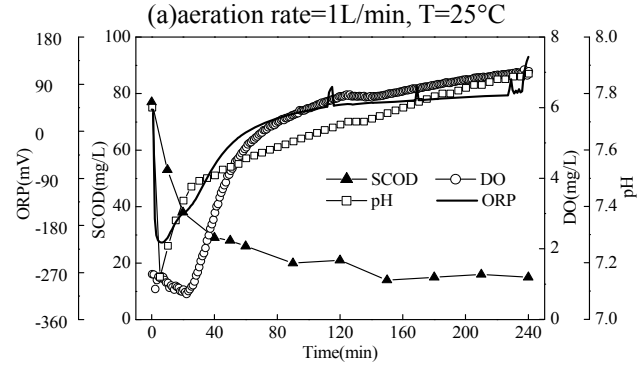

(b)aeration rate $=0.51 / \mathrm{min}, \mathrm{t}=25^{\circ} \mathrm{c}$

FIGURE II. THE CORRESPONDENCE BETWEEN ORGANICS REMOVAL PROCESS AND DO, PH AND ORP

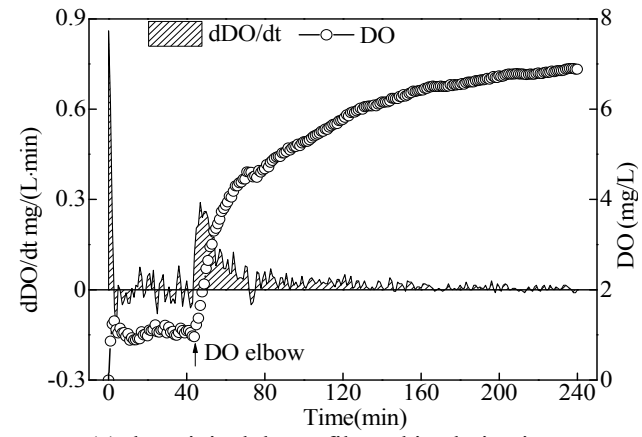

(a) the original do profile and its derivatives

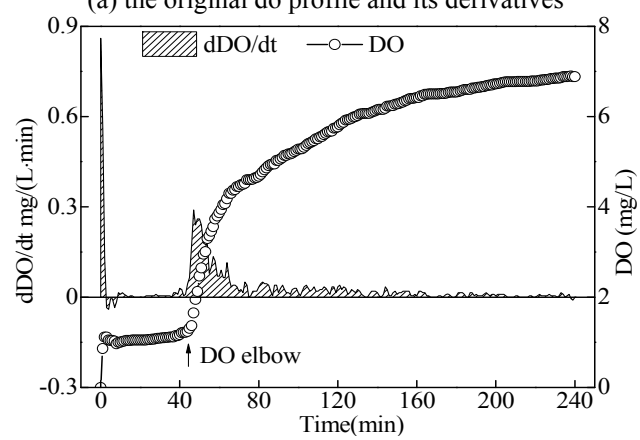

(b) the smoothed DO profile and its derivatives

FIGURE III. THE ORIGINAL AND SMOOTHED DO PROFILES AND THEIR DERIVATIVES IN THE REACTION STAGE (AERATION RATE OF 1.0 L/MIN)

In contrast with OPR and $\mathrm{pH}$ profiles, the $\mathrm{DO}$ profiles were able to duplicate the feature points (DO elbow), corresponding to the completion of organics degradation under all the operation conditions. Upon beginning aeration, a rapid increase of DO occurred within a short period of time. This increase in the DO values appears to correspond to the provision of air. Then DO appeared short-time reduction with a subsequent platform. The value of the platform varied with the operation conditions (Figure 2). Once the organic degradation completed, the DO profiles displayed a constant and remarkable raise and the DO elbow appeared. Therefore, the feature points observed in DO profiles indicate to have the potential for real-time control of the organic removal SBR based on photovoltaic aeration.

Detecting relative changes in sensor profiles (calculated by first derivative or second derivative) provided a more reliable control strategy for nutrient removal in SBRs [11,30,31]. The original DO signals and their derivatives, however, are contaminated by a substantial amount of high-frequency noise (Figure 3a). Therefore, they must be pre-processed with digital filters to obtain good signal smoothing result, at the same time, the feature points are fairly preserved (Figure $3 b$ ). With the aid of computer and data acquisition system, these points can be readily recognized and timely applied for the process control.

\section{CONCLUSIONS}

The SBR based on photovoltaic aeration for organic removal was feasible for rural sewage treatment in those area with abundant solar energy to reduce the energy consumption or even make the wastewater treatment facilities self-sufficient. Efficient removal of SCOD can always be achieved under different operational conditions.

Significant points for real-time control were identified in DO profiles. Slope changes in DO profiles $(\mathrm{d} D O / \mathrm{d} t)$ were found to better represent the organic degradation process, which could be used for real-time control of the organics removal process after smoothing.

\section{ACKNOWLEDGMENT}

We gratefully acknowledge the financial support from the Major Science and Technology Project of Water Pollution Control and Management.

\section{REFERENCES}

[1] Gong L X, Jun L, Yang Q, et al. Biomass characteristics and simultaneous nitrification-denitrification under long sludge retention time in an integrated reactor treating rural domestic sewage $[\mathrm{J}]$. Bioresource Technology. 2012, 119: 277-284.

[2] Ye F X, Li Ying. Enhancement of nitrogen removal in towery hybrid constructed wetland to treat domestic wastewater for small rural communities[J]. Ecological Engineering. 2009, 35(7): 1043-1050.

[3] Li S, Li H, Liang X Q, et al. Rural wastewater irrigation and nitrogen removal by the paddy wetland system in the Tai Lake region of China[J]. Journal of Soils and Sediments. 2009, 9(5): 433-442.

[4] Markus S, Norbert B, Thor-Axel S. Why do water and sanitation systems for the poor still fail? Policy analysis in economically advanced developing countries[J]. Environmental Science and Technology. 2013, 47(12): 6102-6110.

[5] Maggie A M, Menachem E. Water and sanitation in developing countries: including health in the equation[J]. Environmental Science and Technology. 2007, 41(1): 17-24.

[6] Han C F, Liu J X, Liang H W, et al. An innovative integrated system utilizing solar energy as power for the treatment of decentralized wastewater[J]. Journal of Environmental Sciences. 2013, 25(2): 274-279. 
[7] Rani D, Dahiya R P, Ashok K, et al. Meeting energy requirement of wastewater treatment in rural sector[J]. Energy Policy. 2007, 35(7): 3891-3897.

[8] Ma F S, Zhou B H, Li L, et al.Application of photovoltatic technology to rural sewage treatment[J]. Water and wastewater.2012(S1):150-154. (in Chinese)

[9] Ga C H, Ra C S. Real-time control of oxic phase using pH (mV)-time profile in swine wastewater treatment[J]. Journal of Hazardous Materials. 2009, 172(1): 61-67.

[10] Ra C S, Lo K V, Mavinic D S. Control of a swine manure treatment process using a specific feature of oxidation reduction potential[J]. Bioresource Technology. 1999, 70(2): 117-127.

[11] Martín de la Vega P T, Martínez de Salazar E, Jaramillo M A, et al. New contributions to the ORP and DO time profile characterization to improve biological nutrient removal[J]. Bioresource Technology. 2012, 114(0): 160-167.

[12] Chang C N, Ma Y S, Lo C W. Application of oxidation-reduction potential as a controlling parameter in waste activated sludge hydrolysis[J]. Chemical Engineering Journal. 2002, 90(3): 273-281.

[13] Chang C N, Cheng H B, Chao A C. Applying the Nernst equation to simulate redox potential variations for biological nitrification and denitrification processes[J]. Environmental Science and Technology. 2004, 38(6): 1807-1812.

[14] Han Z Y, Wu W X, Zhu J, et al. Oxidization-reduction potential and $\mathrm{pH}$ for optimization of nitrogen removal in a twice-fed sequencing batch reactor treating pig slurry[J]. Biosystems Engineering. 2008, 99(2): 273-281.

[15] Liu W, Henrik L, Brian V M, et al. Potential of renewable energy systems in China[J]. Applied Energy. 2011, 88(2): 518-525.

[16] APHA, Standard Methods for the Examination of Water and Wastewater. 20th ed. American Public Health Association, Washington DC. 1998.

[17] Tang X X, Ma B, Xu Z B, et al. Preices separation of organic removal and nitrification process and real-time control method of a autotrophic nitrogen removal process[J]. CIESC Journal, 2012, 63(11): 3666-3672. (in Chinese)

[18] Zeng W, Peng Y Z, Wang S Y. A two-stage SBR process for removal of organic substrate and nitrogen via nitrite-type nitrification-denitrification[J]. Journal of Environmental Science and Health Part A-Toxic/Hazardous Substances and Environmental Engineering. 2004, 39(8): 2229-2239.

[19] Hu A H, Zheng P, Jin R C. Mechanism of effect of anoxic stress on nitrification[J]. CIESC Journal. 2007, 58(10): 2587-2594. (in Chinese)

[20] Adrian O, Paulo C L, Gilda C, et al. Advances in enhanced biological phosphorus removal: From micro to macro scale[J]. Water Research. 2007, 41(11): 2271-2300.

[21] Mino T, van Loosdrecht M C M, Heijnen J J. Microbiology and biochemistry of the enhanced biological phosphate removal process[J]. Water Research. 1998, 32(11): 3193-3207.

[22] Tu Y J, Andrew J. Schuler. Low acetate concentrations favor polyphosphate-accumulating organisms over glycogen-accumulating organisms in enhanced biological phosphorus removal from wastewater[J]. Environmental Science and Technology. 2013, 47(8): 3816-3824.

[23] Thongchai P, Apiradee D, Jin A. Temperature effect on microbial community of enhanced biological phosphorus removal system[J]. Water Research. 2003, 37(2): 409-415.

[24] Whang L M, Park J K. Competition between polyphosphate- and glycogen-accumulating organisms enhanced-biological-phosphorus-removal systems: Effect of temperature and sludge age[J]. Water Environment Research. 2006, 78(1): 4-11.

[25] Carlos M L V, Christine M. H, Damir B, et al. Temperature effects on glycogen accumulating organisms[J]. Water Research. 2009, 43(11): 2852-2864.

[26] Duncan J B , David C S . A review of soluble microbial products (SMP) in wastewater treatment systems[J]. Water Research. 1999, 33(14): 3063-3082.

[27] Pankaj T, Tapas N, Pallavi U, et al. Correlating on-line monitoring parameters, $\mathrm{pH}, \mathrm{DO}$ and ORP with nutrient removal in an intermittent cyclic process bioreactor system[J]. Bioresource Technology. 2008, 99(16): 7630-7635.

[28] Li B K, Irvin S. The comparison of alkalinity and ORP as indicators for nitrification and denitrification in a sequencing batch reactor (SBR)[J]. Biochemical Engineering Journal. 2007, 34(3): 248-255.

[29] Chao H C, Oliver J H. Sequencing batch reactor system for nutrient removal: ORP and $\mathrm{pH}$ Profiles[J]. Journal of Chemical Technology and Biotechnology. 1996, 67(1): 27-38.

[30] Casellas M, Dagot C, Baudu M. Set up and assessment of a control strategy in a SBR in order to enhance nitrogen and phosphorus removal[J]. Process Biochemistry. 2006, 41(9): 1994-2001.

[31] Ruano M V, Ribes J, Seco A, et al. An advanced control strategy for biological nutrient removal in continuous systems based on $\mathrm{pH}$ and ORP sensors[J]. Chemical Engineering Journal. 2012, 183(0): 212-221. 